\title{
AVALIAÇÃO DO COMPORTAMENTO MAGNÉTICO, APÓS CONFORMAÇÃO MECÂNICA, NOS AÇOS INOXIDAVEIS AUSTENÍTICOS AISI 304 E AISI 316L
}

\author{
EVALUATION OF THE MAGNETIC BEHAVIOR, AFTER MECHANICAL \\ CONFORMATION, OF AISI 304 AND AISI 316L AUSTENITIC STAINLESS STEEL
}

\author{
Alessandro Fraga Farah ${ }^{\mathrm{I}}$ \\ Solange Pereira dos Santos Farah ${ }^{\mathrm{II}}$ \\ Omar Maluf ${ }^{\mathrm{III}}$ \\ Alessandro Márcio Hakme da Silva ${ }^{\mathrm{IV}}$ \\ Edson Luis Boldrin ${ }^{\mathrm{V}}$
}

\begin{abstract}
RESUMO
Os aços inoxidáveis têm sido amplamente utilizados nas indústrias nucleares, químicas e petroquímicas, devido às suas excelentes propriedades mecânicas e de resistência à corrosão, especialmente em ambientes agressivos e em muitos casos são utilizados os aços inoxidáveis da série 300 por não conter magnetismo. Entretanto, esses aços quando são submetidos a um processo de conformação mecânica, passam a apresentar magnetismo na parte externa da peça que sofreu a deformação. Este estudo tem como objetivo identificar alterações magnéticas e microestruturais sofridas pelos aços após passarem por processo de conformação. Foram feitas análises em dois aços inoxidáveis, o AISI 304 e o AISI 316L, que passaram por processo de conformação mecânica (dobramento) e após isso foram feitas análises da microestrutura através de microscopia óptica e análise de magnetismo através de um Ferritoscópio.
\end{abstract}

Palavras-chave: Aço Inoxidável Austenítico. Magnetismo; Conformação.

\begin{abstract}
Stainless steels have been widely used in nuclear, chemical, and petrochemical industries, due to their excellent mechanical properties and corrosion resistance, especially in aggressive environments and in many cases stainless steels of the 300 series are used because they do not contain magnetism. However, when these steels are subjected to a mechanical forming process, they start to present magnetism on the outside of the part that underwent the deformation. This study aims to identify magnetic and microstructural changes suffered by steels after undergoing a conforming process. Analyzes were carried out on two stainless steels, AISI 304 and AISI 316L, which underwent a mechanical conformation process

I Prof. Dr. da Faculdade de Tecnologia Deputado Waldyr Alceu Trigo de Sertãozinho (Fatec-Stz) - São Paulo Brasil. E-mail: alessandro.farah@fatec.sp.gov.br

II Profa. Mestre da Faculdade de Tecnologia Deputado Waldyr Alceu Trigo de Sertãozinho (Fatec-Stz) - São Paulo - Brasil. E-mail: solangepfarah@gmail.com

III Prof. Dr. da Faculdade de Tecnologia Deputado Waldyr Alceu Trigo de Sertãozinho (Fatec-Stz) - São Paulo Brasil. E-mail: omar.maluf@fatec.sp.gov.br

IV Prof. Dr. da Faculdade de Tecnologia Deputado Waldyr Alceu Trigo de Sertãozinho (Fatec-Stz) - São Paulo Brasil. E-mail: alessandro.silva72@fatec.sp.gov.br

V Tecnólogo em Mecânica: Processos de Soldagem. Auxiliar Docente da Faculdade de Tecnologia Deputado Waldyr Alceu Trigo de Sertãozinho (Fatec-Stz) - São Paulo - Brasil. E-mail: edson.boldrin@fatec.sp.gov.br
\end{abstract}




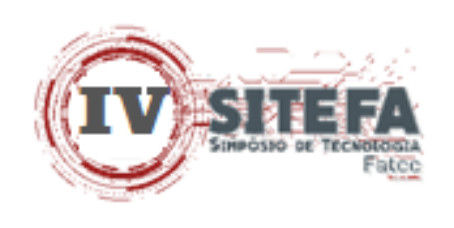

(folding) and after that, microstructure analyzes were performed using optical microscopy and magnetism analysis using a Ferritoscope.

Keywords: Austenitic Stainless Steel. Magnetism; Conforming Process.

Data de submissão do artigo: 30/06/2021.

Data de aprovação do artigo: 19/08/2021.

DOI: $10.33635 /$ sitefa.v4i1.181

\section{INTRODUÇÃO}

Os aços inoxidáveis são materiais utilizados em situações que demandam além de boa resistência à corrosão, uma boa resistência mecânica. Os aços inoxidáveis são classificados de acordo com a fase predominante na sua microestrutura, ferríticos, austeníticos e martensíticos (CHIAVERINI, 2008). Dentre eles os austeníticos, produzidos em larga escala, apresentam maior resistência à corrosão devido à alta concentração de cromo e níquel, entretanto, esses não são magnéticos, diferentemente dos ferríticos e martensíticos (MARTINS, 2016). Embora os aços inoxidáveis austeníticos, praticamente, não sejam susceptíveis à transformação de fases martensíticas por têmpera, esses materiais podem sofrer transformações martensíticas quando são deformados plasticamente. Isso pode ocorrer com maior ou menor intensidade, dependendo da composição química do material e do estado de tensões aplicado.

Baseado nessa propriedade surgiu a necessidade de estudar a transformação de aços inoxidáveis austeníticos quando submetidos a uma conformação mecânica. Para tanto dois aços inoxidáveis da série 300, o AISI 304 e o AISI 316L foram submetidos a deformação plástica e depois analisados para avaliar o aumento da intensidade magnética na região deformada, assim como a mudança de dureza e microestrutura após a deformação.

\section{AÇOS INOXIDÁVEIS}

Aços inoxidáveis são ligas de ferro $(\mathrm{Fe})$ e cromo $(\mathrm{Cr})$ com um mínimo de $11 \%$ de $\mathrm{Cr}$. Outros elementos metálicos também integram estas ligas, mas o $\mathrm{Cr}$ é considerado o elemento mais importante porque é o que dá aos aços inoxidáveis uma elevada resistência à corrosão. São muito importantes na engenharia, em função da sua resistência à oxidação e à corrosão, propriedades mecânicas e temperaturas elevadas e tenacidade (CHIAVERINI, 2008; SILVA e MEI, 2006).

Segundo Silva, M. et al., (2016) e Chiaverini (2008), além do cromo podem ser adicionados outros elementos químicos, a fim de melhorar determinadas propriedades do material. Dentre os tipos de aços inoxidáveis produzidos estão os aços inoxidáveis austeníticos, ferríticos e martensíticos. Estas microestruturas podem ser obtidas ajustando adequadamente a composição química e os tratamentos térmicos do aço (SILVA e MEI, 2006). Segundo Martins (2016), a partir destas três microestruturas principais podem ser categorizadas outras classes como os duplex e os endurecíveis por precipitação.

O tópico a seguir fará uma abordagem aos aços inoxidáveis austeníticos, que são os objetos de estudo deste trabalho. 


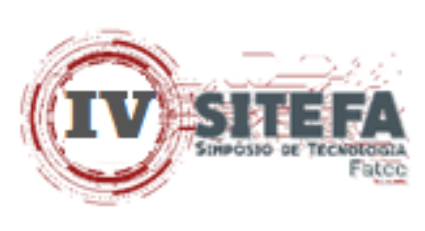

\subsection{Aços inoxidáveis austeníticos}

São ligas de ferro, cromo e níquel (Ni). A introdução do níquel melhora consideravelmente a resistência a corrosão e a resistência a oxidação em altas temperaturas. Em geral são não magnéticos, tem boa soldabilidade e não são endurecíveis por tratamento térmico, por já serem austeníticos (SILVA L., 2016; CHIAVERINI, 2008). A adição de níquel como elemento de liga, em determinadas quantidades, permite transformar a estrutura ferrítica em austenítica, o que lhes garante uma estrutura CFC (Cúbica de Face Centrada), e isso tem como consequência uma grande mudança em propriedades químicas, físicas e mecânicas (SILVA, M. et al., 2016; TULER; CAETANO, 2016). Segundo Martins (2016), outra característica desse material é que eles não são ferromagnéticos, podendo ser utilizados em ambientes onde materiais suscetíveis ao magnetismo não podem ser utilizados.

De acordo com Nery (2018), o níquel amplia o campo de estabilidade da austenita, retarda as transformações de fase no estado sólido e abaixa as temperaturas de início de transformação martensítica (Mi) e de fim de transformação martensítica (Mf).

$\mathrm{O}$ trabalho a frio também influencia nas propriedades mecânicas e magnéticas do aço inoxidável. Mesmo que os aços inoxidáveis austeníticos sejam não-magnéticos na condição recozida, eles podem desenvolver uma resposta magnética quando trabalhados a frio. $\mathrm{O}$ trabalho a frio pode transformar um pouco de austenita em martensita, e isto tem um efeito na resistência mecânica do aço (SILVA L., 2016; MORAIS, 2010)

Segundo Torquato et al. (2019) e Morais (2010), quando são encruados, apresentam um fenômeno interessante: o aumento de dureza que se verifica é bem superior ao que se encontraria, mediante a deformação em outros aços. Esse aumento pode ser atribuído a instabilidade da austenita que, sob os efeitos das tensões do encruamento, transforma-se parcialmente em ferrita. Essa ferrita, supersaturada de carbono, nas mesmas condições que uma martensita, contribui para o endurecimento do aço.

De acordo com Silva L. (2016), os aços austeníticos não são magnéticos, mas após um processo de estampagem, ou em uma conformação a frio, como na laminação, pode ser observado certo caráter magnético nas partes que sofreram maior deformação. Isso é consequência da transformação parcial da austenita em martensita, que ocorre por deformação a frio. $\mathrm{O}$ aquecimento a temperaturas moderadas desse aço encruado restaura a austenita.

\subsection{Aços Inoxidáveis Austeníticos AISI 304 e AISI 316L}

Dentre os aços inoxidáveis austeníticos, o AISI $304(18 \% \mathrm{Cr}-8 \% \mathrm{Ni})$ é um dos mais utilizados, pois tem excelente resistência à corrosão, excelente ductilidade e excelente soldabilidade. É um material com grandes possibilidades em suas aplicações, pois podemos encontrá-lo em nossas casas (garfo ou panela, por exemplo) como também em uma vasta área industrial (indústria alimentícia, aeronáutica, ferroviária, petrolífera, química e petroquímica, papel e celulose, construção civil etc.) (TORQUATO et al. 2019; MORAIS,2010).

De acordo com Souza (2017), o aço inoxidável austenítico AISI 316L, que apresenta um teor máximo de carbono de $0,03 \%$, também é bastante utilizado na indústria metalmecânica, por sua excelente resistência à corrosão e conformabilidade. Contudo, em algumas situações, sua aplicação é prejudicada pela baixa resistência mecânica.

Entre as aplicações mais importantes desse aço pode-se destacar: válvulas, tubos, pararaios, equipamentos para as indústrias químicas, petróleo e gás, farmacêuticas, papel e celulose, entre outras (SOUZA, 2017). 


\section{(i.j)}

\subsection{Magnetismo em Aços Inoxidáveis Austeníticos}

A resposta magnética ou a falta dela é algumas vezes uma propriedade requerida em aplicações de aços inoxidáveis. Segundo Torquato et al. (2019) e Nery (2018), a maioria dos aços inoxidáveis austeníticos, tanto da série 300 quanto da série 200, não são magnéticos.

Entretanto esses aços inoxidáveis austeníticos têm composições ligeiramente diferentes entre suas classes e o pequeno percentual de ferrita presente na sua microestrutura resulta em uma pequena quantidade de resposta magnética. Normalmente isso não é suficiente para afetar significativamente o desempenho magnético, exceto em aplicações muito críticas (TORQUATO et al., 2019; NERY, 2018; MORAIS, 2010).

De acordo com Nery (2018) e Morais (2010), o trabalho a frio também influencia nas propriedades magnéticas do aço inoxidável. Mesmo que os aços inoxidáveis austeníticos sejam não-magnéticos na condição recozida, eles podem desenvolver uma resposta magnética quando trabalhados a frio.

De acordo com Torquato et al. (2019) e Morais (2010), um aço AISI 304 altamente deformado será fortemente atraído por um ímã. Grades com maiores quantidades de elementos formadores de austenita - níquel, manganês, carbono, cobre e nitrogênio - formam menos martensita quando trabalhados a frio, por isso não se tornam tão fortemente magnéticos. Isto pode ser avaliado como a razão entre os elementos formadores da austenita divididos por elementos formadores de ferrita, simplesmente como a razão Ni / Cr.

Ainda segundo Torquato et al. (2019) e Morais (2010), os aços da classe 316 geralmente só se tornam levemente magnéticos não importando o grau de severidade do trabalho a frio.

\section{PROCEDIMENTOS METODOLÓGICOS}

Para caracterizar o comportamento dos aços analisados, quanto às condições de dureza, microestruturais e magnéticas, as amostras foram submetidas aos ensaios de dobramento, metalográficos, de dureza e ferritoscopia. Cada etapa da metodologia apresentou resultados que ajudaram a entender o comportamento das amostras analisadas.

\subsection{Materiais}

Foram utilizados dois tipos de aços inoxidáveis, um AISI 304 e um AISI 316L. A composição química dos aços utilizados está na Tabela 1.

Tabela 1 - Composição Química dos Aços Inoxidáveis Austeníticos

\begin{tabular}{c|c|c|c|c|c|c|c|c|c}
\hline \multicolumn{10}{c}{ Composição Química (\%) } \\
\hline Aço & $\mathrm{C}$ & $\mathrm{Mn}$ & $\mathrm{Si}$ & $\mathrm{P}$ & $\mathrm{S}$ & $\mathrm{Cr}$ & $\mathrm{Ni}$ & Mo & $\mathrm{Fe}$ \\
\hline AISI 304 & 0,056 & 1,11 & 0,52 & 0,026 & 0,001 & 18,01 & 8,02 & 0,036 & Bal. \\
\hline AISI 316L & 0,023 & 1,34 & 0,48 & 0,035 & 0,001 & 16,68 & 10,01 & 2,021 & Bal. \\
\hline
\end{tabular}

Fonte: elaborada pelos autores (2021)

Para realizar o dobramento da chapa foi utilizado um corpo de prova de cada aço inoxidável contendo as seguintes medidas: $150 \mathrm{~mm} \times 50 \mathrm{mmx} 4 \mathrm{~mm}$ corpo de prova do aço inoxidável AISI 304 e outro corpo de prova de aço inoxidável AISI 316L. As Figuras 1 (a) e (b), mostram as chapas dobradas dos aços AISI 304 e AISI 316L, respectivamente. 
Figura 1 - Chapas dobradas dos Aços Inoxidáveis Austeníticos. (a) AISI 304; (b) AISI 316L
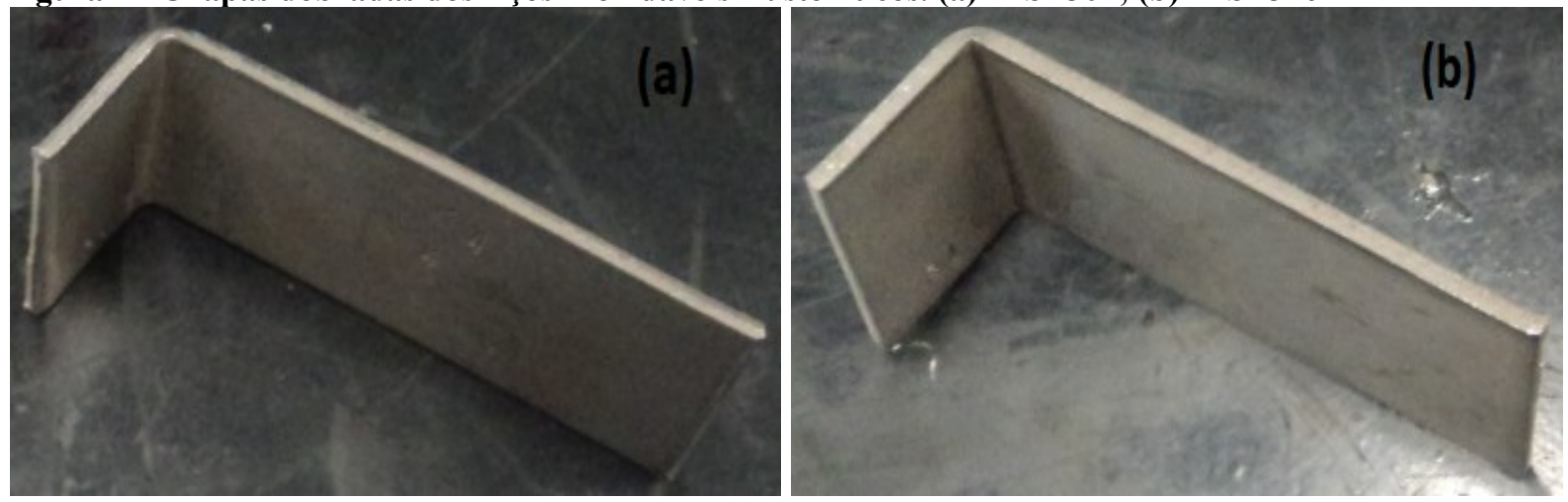

Fonte: os autores (2021)

\subsection{Métodos}

As chapas foram dobradas em dobradeira industrial em ângulo de $90^{\circ}$. Após o dobramento a chapa foi cortada e retirado um pedaço para fazer o ensaio metalográfico.

O ensaio metalográfico foi feito de acordo com os procedimentos sugeridos por Colpaert (2008). Após realizado o polimento da amostra, foi feito um ataque químico com Água Régia para se observar, com o auxílio de um microscópio óptico, a microestrutura presente nas amostras.

As análises da quantidade de ferrita presente nos corpos de prova foi feita utilizando um Ferritoscópio modelo Fisher FMP30. Segundo Morais (2010), o Ferritoscópio aplica um campo magnético para determinar a quantidade de fase ferromagnética presente na amostra. $\mathrm{O}$ resultado obtido é dado em percentagem.

As medições de dureza foram feitas em Durômetro de bancada tipo Rockwell, utilizando a escala $\mathrm{B}$, esfera de aço com $100 \mathrm{~kg}$ de carga. As medições foram feitas na região não deformada das amostras e, também, na região dobrada.

\section{RESULTADOS E DISCUSSÃO} nessa seção.

Os resultados encontrados nas análises laboratoriais serão mostrados e discutidos

\subsection{Resultados obtidos do ferristoscópio}

A análise com o Ferritoscópio, mediu a intensidade do magnetismo em diversos pontos das amostras e obteve-se os seguintes resultados.

O magnetismo encontrado nas amostras dos aços inoxidáveis AISI 304 e AISI 316L, são mostrados na Figura 2. 


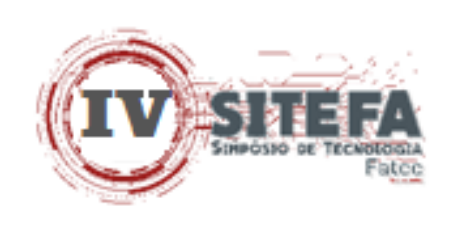

Figura 2 - Percentual de magnetismo obtido na amostra do aço inoxidável AISI 304
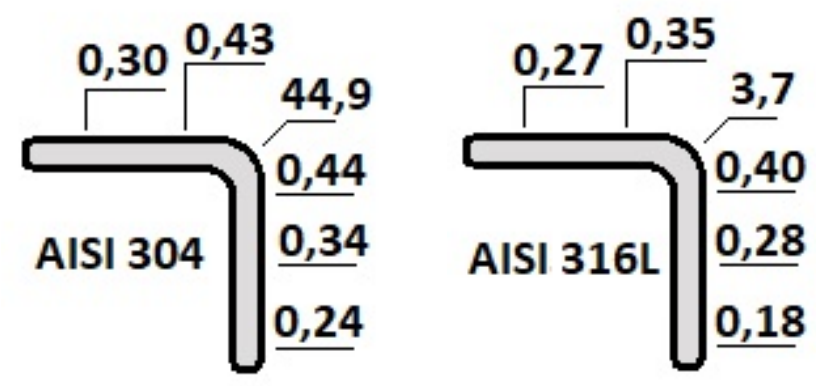

Fonte: os autores (2021)

Nos pontos que estão mais distantes do ponto que foi dobrado, a quantidade de magnetismo foi bem menor quando comparada com a região da deformação plástica obtida por dobramento. Nota-se também que a quantidade de magnetismo no aço AISI 304 foi maior que no aço AISI 316L. A quantidade de magnetismo média, da região não deformada foi de 0,350 para o AISI 304 e de 0,296 para o AISI 316L.

\subsection{Resultados obtidos do ensaio de dureza}

Os resultados de dureza apresentados na Tabela 2 são uma média de cinco medições efetuadas nas diferentes regiões de cada amostra.

Tabela 2 - Durezas encontradas nas amostras dos Aços Inoxidáveis Austeníticos

\begin{tabular}{c|c|c}
\hline \multicolumn{2}{c}{ Dureza (HRB) } \\
\hline Aço & Região Não Deformada & Região Deformada \\
\hline AISI 304 & 89,9 & 98,1 \\
\hline AISI 316L & 82,3 & 88,0 \\
\hline
\end{tabular}

Fonte: os autores (2021)

Nota-se na Tabela 2 que as durezas médias tiveram um aumento na região deformada em relação à região não deformada. Esse aumento é devido ao encruamento e/ou pela martensita induzida por deformação.

\subsection{Resultados obtidos da metalografia}

Os resultados das análises microscópicas são mostrados a seguir.

A Figura 3 (a) e (b) mostra a microestrutura do aço AISI 304 na região não deformada e na região deformada, respectivamente.

Nota-se na Figura 3 (a) a presença de grãos austeníticos maclados, típicos de microestrutura austenítica. Na Figura 3 (b) é possível verificar a deformação do grão austenítico, com algum cisalhamento, típico de martensita. Esses resultados corroboram os estudos de Torquato et al. (2019), Nery (2018), Souza (2017) e Morais (2010). 
Figura 3 - Aço AISI 304. (a) Região Não Deformada. (b) Região Deformada. Ataque: Água Régia. Aumento: 200x.

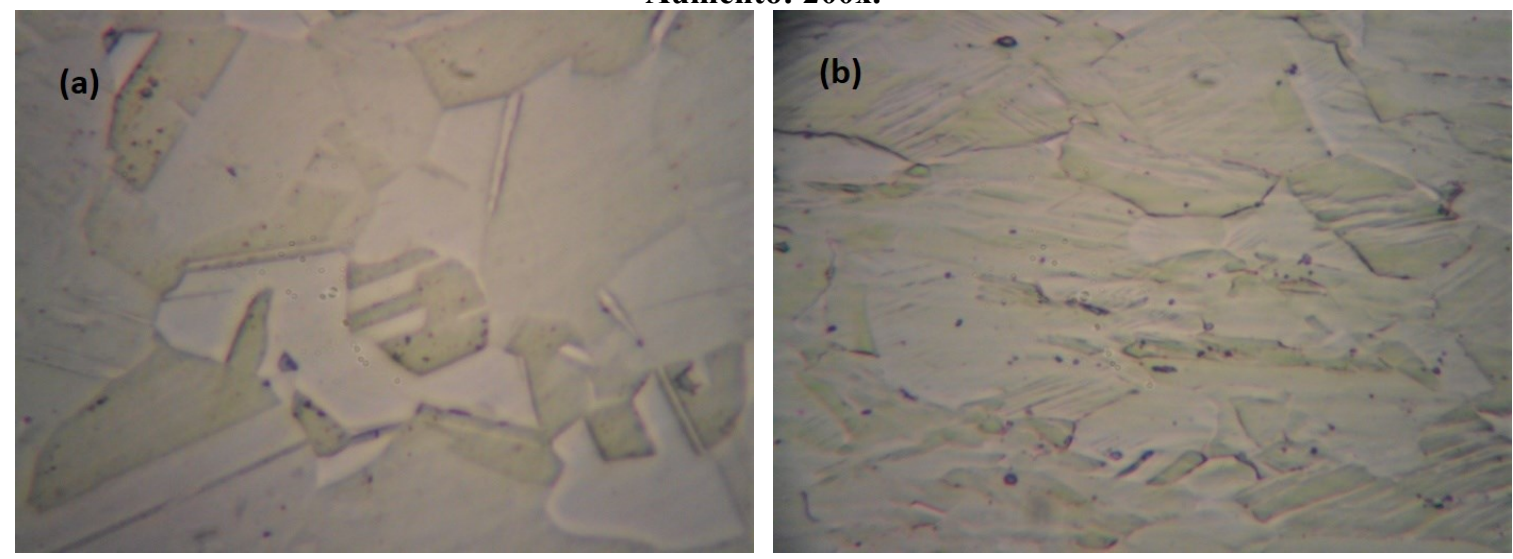

Fonte: os autores (2021)

A Figura 4 (a) e (b) mostra a microestrutura do aço AISI 316L na região não deformada e na região deformada, respectivamente.

Observa-se que a microestrutura da Figura 4 (a) é composta de grãos austeníticos maclados, típica de aços inoxidáveis austeníticos. Na Figura 4 (b) podemos ver os grãos austeníticos deformados e com aspecto de martensita induzida por deformação. Também há semelhanças com os resultados dos estudos de Torquato et al. (2019), Nery (2018), Souza (2017) e Morais (2010).

Figura 4 - Aço AISI 316L. (a) Região Não Deformada. (b) Região Deformada. Ataque: Água Régia. Aumento: 200x.
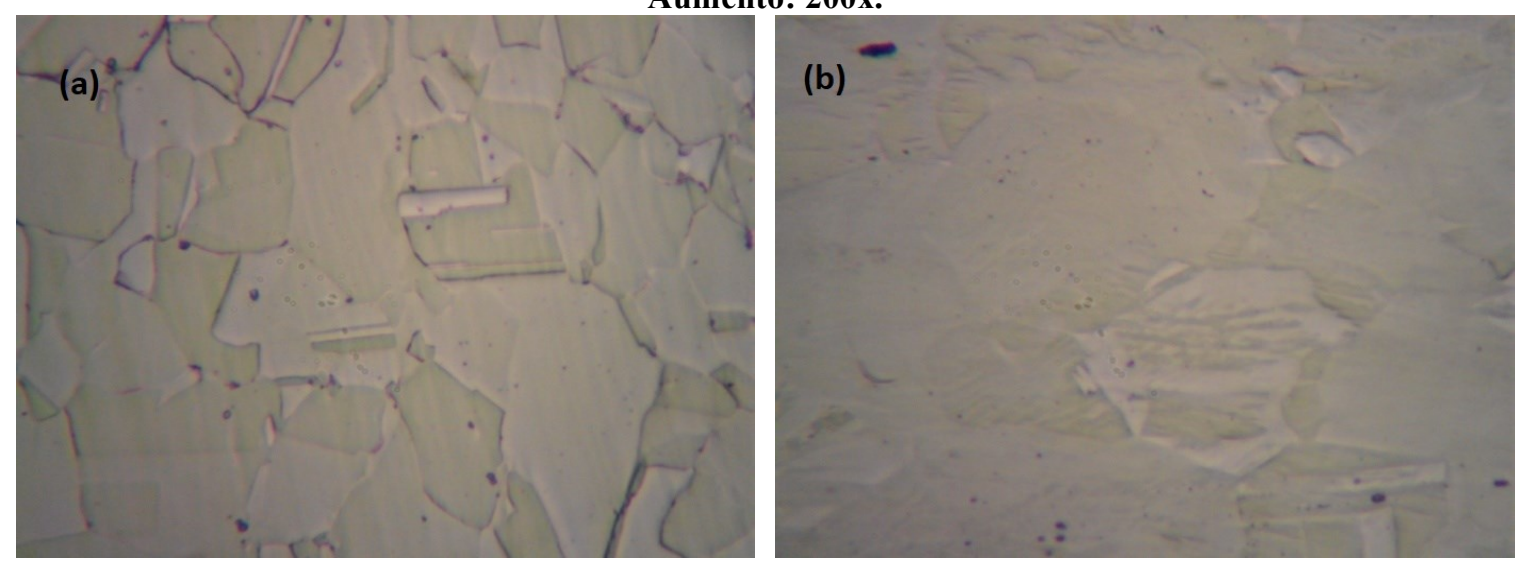

Fonte: os autores (2021)

\section{CONCLUSÃO}

Através dos resultados obtidos e os dados presentes na revisão da literatura é possível concluir que os materiais analisados passam a apresentar magnetismo após a conformação devido à transformação parcial de austenita em martensita. Essa transformação é devido à instabilidade da austenita que, sob os efeitos das tensões do encruamento, transforma-se parcialmente em martensita.

O maior percentual de Níquel no aço AISI 316L aumentou a estabilização da austenita, diminuindo a transformação de martensita induzida e consequentemente o 


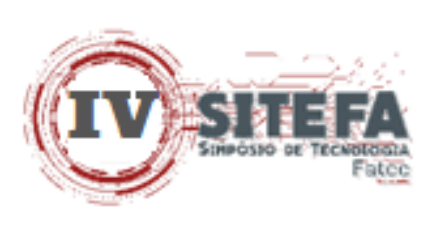

percentual de magnetismo. Elementos formadores de austenita em maiores quantidades formam menos martensita quando deformados a frio.

A maior variação de dureza do aço AISI 304 em relação à região deformada deve-se à maior capacidade de se transformar em martensita por encruamento.

Esse trabalho pode auxiliar na escolha de aços inoxidáveis em aplicações onde além da resistência à corrosão/oxidação, a alteração da indução eletromagnética pode ser um problema, como é o caso de componentes elétricos e ambientes inflamáveis.

\section{REFERÊNCIAS}

CHIAVERINI, Vicente. Aços e ferros fundidos: características gerais, tratamento térmico. 7 . ed. São Paulo, Associação Brasileira de Metalurgia e Materiais, 2008.

COLPAERT, Hubertus. Metalografia dos produtos metalúrgicos comuns. Revisão Técnica: André Luiz V. da Costa e Silva - 4. ed.- São Paulo: Edgar Blucher, 2008.

MARTINS, Divino Diogo do Nascimento. Caracterização do comportamento eletroquímico do aço ASTM A743 CA6NM após soldagem GMAW com metal de adição AWS 5.22 EC410NiMo. Dissertação de Mestrado em Ciências Mecânicas. Departamento de Pós-Graduação em Ciências Mecânicas, Universidade de Brasília, Brasília, DF, 93p. 2016.

MORAIS, Viviane Lima de. Estudo comparativo da deformação a frio e da resistência à corrosão nos aços inoxidáveis austeníticos AISI 201 e AISI 304. Dissertação (Mestrado). Escola Politécnica da Universidade de São Paulo. Departamento de Engenharia Metalúrgica e de Materiais. 144p. São Paulo-SP. 2010.

NERY, Macclarck Pessoa. Efeito da tensão média e frequência na resistência a fadiga e corrosão-fadiga de parafusos prisioneiros de aço inoxidável AISI 304. Dissertação (mestrado em Ciência e Engenharia de Materiais) - Universidade Federal de Sergipe, 2018.

SILVA, André Luiz V. da Costa e; MEI, Paulo Roberto. Aços e ligas especiais. Editora Edgard Blücher, 2. ed, São Paulo, 2006.

SILVA, Lucas Kling e; SILVA, Vitor Manoel de Araújo; PACHECO, Clara Johanna; PEREIRA, Gabriela Ribeiro. Caracterização magneto-óptica de aço inoxidável austenítico deformado a frio. Contribuição técnica ao $71^{\circ}$ Congresso Anual da ABM - Internacional e ao $16^{\circ}$ ENEMET - Encontro Nacional de Estudantes de Engenharia Metalúrgica, de Materiais e de Minas, parte integrante da ABM Week, 26 a 30 de setembro, Rio de Janeiro, RJ, Brasil. 2016.

SILVA, Marcela Alves; BATISTA, Beatriz Araújo; BATISTA, Luana Araújo. Caracterização de um aço inoxidável duplex em comparação a aços inoxidáveis ferriticos e austeníticos em relação à microestrutura e propriedades mecânicas em tração. Contribuição técnica ao $71^{\circ}$ Congresso Anual da ABM - Internacional e ao $16^{\circ}$ ENEMET - Encontro Nacional de Estudantes de Engenharia Metalúrgica, de Materiais e de Minas, parte integrante da ABM Week, 26 a 30 de setembro, Rio de Janeiro, RJ, Brasil. 2016. 


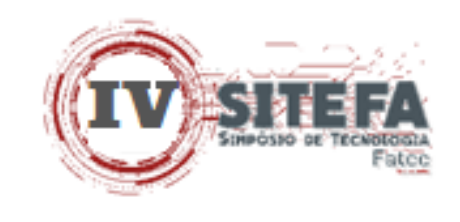

SOUZA, Marcel Freitas de. Estudo das propriedades mecânicas e tensões residuais de juntas soldadas de aço AISI 316L. Dissertação (Mestrado em Engenharia Mecânica). Universidade Federal Fluminense, Niterói, RJ. 2017.

TORQUATO, Helder Maia; ALVES, Lázaro Alano Almeida; SILVA, Milton Sérgio Mendes; FERREIRA, Thiago Alencar Luna; LUCAS, Wildenbergy Pereira. Estudo de risco devido ao acúmulo de energia estática em bicos de enchimento fabricados com aço inoxidável austenítico aisi 304 após deformação. Prêmio Case 2019. Disponível em:

http://www.gasescombustiveis.com.br/premioglp/?p=3708. Acesso em: 20 jun. 2021.

TULER, Grazieli Viana; CAETANO, Skarllet Toledo. Resolução do Problema do Aço Inoxidável da Empresa Aperam. Revista Científica Univiçosa - v. 8 - n. 1; p. 848-854. Viçosa - MG - jan. - dez. 2016. 